\title{
Media Pembelajaran Interaktif Berbasis Software Fruity Loops Untuk Meningkatkan Pembelajaran Mata Kuliah Tata Suara
}

\author{
Yunanto Tri Laksono1, Ardian Jaya Prasetyo2, Dhika Yuan Yurismaz \\ Institut Bisnis dan Informatika \\ STIKOM Surabaya \\ yunanto@stikom.edu1,ardian@stikom.edu2,dhika@stikom.edu3
}

\begin{abstract}
Art technology is a field of science related to the 4.0 era, through art software and hardware trying to follow patterns and forms in the creation and rearrangement in the art production process. The relation of art is not far from the development of methods in learning that are related to the system and the way of teaching. Some institutions / universities in the art of music learning system have especially developed compositions and arrangements using software. Problems that arise in the process of learning and teaching activities are still experienced both in terms of the methods taught and in terms of the material provided, so the learning and teaching processes are less able to develop. The purpose of developing this learning method is to provide convenience for students who specialize in sound courses. Forms of composition and arrangement are more interesting, developing and also more innovative in their creation. The method used is descriptive analysis, which takes from several sample data about this course, assessed from the learning system, the method used in learning, as well as aspects that are less supportive to learning so the need for methodological studies.
\end{abstract}

Keywords: Learning Media, Learning Enhancement, Sound System.

Abstrak: Teknologi seni merupakan bidang ilmu yang berkaitan dengan era 4.0, melalui software dan hardware seni berupaya mengikuti pola dan bentuk dalam penciptaan maupun pengaransemen ulang dalam proses produksi seni. Keterkaitan seni tidak jauh dari pengembangan metode pada pembelajaran yang berkaitan dengan sistem dan cara pengajaran, beberapa Institusi/Universitas pada sistem pembelajaran seni musik khsusunya sudah mengembangkan komposisi dan aransemen menggunakan software. Permasalahan yang muncul pada proses kegiatan belajar dan mengajar masih dialamai baik dari segi metode yang diajarkan maupun dari segi materi yang diberikan, sehingga proses belajar dan mengajar kurang bisa berkembang. Tujuan dari pengembangan metode pembelajaran ini adalah untuk memberikan kemudahan bagi mahasiswa khsusunya yang mengampu mata kuliah tata suara. Bentuk komposisi dan aransemen lebih menarik, berkembang dan juga lebih inovatif dalam penciptaannya. Metode yang digunakan adalah analisis deskiptif, yang mengambil dari beberapa sampel data tentang mata kuliah ini, dinilai dari sistem pembelajaran, metode yang digunakan pada pembelajaran, serta aspekaspek yang kurang menunjang pada pembelajaran sehingga perlu adanya kajian metodologi.

Kata Kunci: Media Pembelajaran, Peningkatan Pembelajaran, Tata Suara.

\section{PENDAHULUAN}

Pendidikan di Indonesia pada umumnya mengalami perubahan yang cukup signifikan, berbagai macam metode dalam proses pembelajaran dikembangkan guna menyesuaikan proses pendidikan yang baik, kreatif, serta inovatif, sehingga memiliki ketercapaian hubungan dengan Kerangka Kualifikasi Nasional Indonesia (KKNI). Era 4.0 juga menjadikan perubahan pada metode pembelajaran yang digunakan karena dengan adanya pembaharuan maka akan mengalami perubahan, karena metode pembelajaran sebelumnya dirasakan masih konvensional, maka perlu adanya perubahan yang lebih futuristik.

Suatu cara atau prosedur yang dipakai untuk mencapai tujuan tertentu. Kata "Pembelajaran" berarti segala upaya yang dilakukan oleh pendidik agar terjadi proses belajar diri peserta didik. Jadi metode pembelajaran adalah cara-cara menyajikan materi pelajaran yang dilakukan oleh pendidik agar terjadi proses belajar pada diri peserta didik dalam upaya untuk mencapai tujuan. (Sutikno, 2014: 33-34). Ditambahkan pula metode pembelajaran sebagai cara yang digunakan guru 
dalam menjalankan fungsinya dan merupakan alat untuk mencapai tujuan pembelajaran. Metode pembelajaran yang digunakan sesuai dengan kebutuhan akan dapat menentukan keberhasilan dalam menyampaikan pembelajaran. (Hamzah dan Nurdin, 2011:7).

Pada undang-undang No. 2 Tahun 2003 tentang Sistem Pendidikan Nasional (Sisdiknas) pasal 1 ayat 20 dijelaskan bahwa pembelajaran merupakan proses interaksi peserta didik dengan pendidik dan sumber belajar pada suatu lingkungan belajar. Suatu sistem atau proses membelajarkan pembelajar yang direncakan, dilaksanakan, dan dievaluasi secara sistematis agar pembelajar dapat mencapai tujuan-tujuan pembelajaran secara efektif dan efisien (Komalasari, 2013:3).

Faktor utama yang melatarbelakangi permasalahan pada pembelajaran yaitu materi dan model pembelajaran yang masih konvensional dengan mengandalkan media analog dan media wacana, sehingga peserta didik mengalami kepasifan. Materi keilmuwan yang diberikan pada mata kuliah tata suara masih berdasarkan penalaran, yang hanya merupakan mata kuliah tambahan dan belum menjadi mata kuliah utama. Pada materi tata suara untuk produksi film, televisi dan juga animasi masih dikembangkan dengan menggunakan metode wacana, dengan cara peserta didik hanya mengamati apa yang disampaikan oleh pendidik, jadi hanya sebatas analisa namun tidak berdasarkan pada analisis studi kasus (case study), yang kemudian dijadikan sebagai salah satu project dalam proses penciptaan komposisi ataupun aransemen tata suara.

Analisis dilakukan untuk mengetahui seberapa paham peserta didik dalam memahami materi yang diberikan sehingga pendidik mengetahui langkah-langkah yang dilakukan dalam penyelesaian masalah pembelajaran. Penggunaan metode pembelajaran yang tepat diharapkan dapat mengurangi tingkat kemampuan peserta didik yang menurun karena faktor kejenuhan, minim inovasi, minim kreativitas, dan juga beberapa faktor yang melatarbelakangi lainnya. Salah satu pokok utama yang dianalisis adalah representasi tentang bagaimana pendidik dapat mengetahui bentuk gelombang suara yang muncul pada sistem tata suara.

Problematika yang juga muncul saat ini adalah bagaimana peserta didik dengan adanya media online belum dapat memaksimalkan bidang keilmuannya, padahal era pengembangan revolus industri 4.0 terus digaungkan untuk mengembangkan keilmuan yang lebih kompetitif dan inovatif.

Secara entitas tata suara harus dipahami menggunakan teori dan praktik, namun pada pelaksanaannya dominasi lebih banyak teori dengan bentuk prosentasenya adalah teori $70 \%$ sedangkan 30\% merupakan praktik. Langkahlangkah sebagai pedoman yang harus dipahami adalah bagaimana peserta didik dapat memahami basic tata suara, balancing suara hingga proses produksi tata suara. Penyeimbangan elemenelemen tugas dari suatu lini perakitan ke stasiun kerja untuk meminimumkan banyaknya stasiun kerja dan meminimumkan total idle time (waktu menganggur) pada semua stasiun untuk tingkat keluaran tertentu. (Gaspersz, 2004).

Pemahaman balancing pada tata suara diperlukan faktor-faktor pendukung lainnya yang menjadi bagian utama yaitu bunyi atau suara. Suatu gelombang berupa getaran dari molekulmolekul zat yang saling beradu satu dengan lainnya secara terkoordinasi sehingga menimbulkan gelombang dan meneruskan energi serta sebagian dipantulkan kembali. Media yang dilalui mempunyai massa yang elastik sehingga dapat mengantarkan bunyi tersebut. (Sarwono, 2002).

\section{KAJIAN PUSTAKA \\ Metode Pembelajaran}

Bagian utama yang sangat mendasar dalam mendukung proses ketercapaian dalam pembelajaran adalah metode. Proses kesesuaian antara materi dan konsep belajar yang baik akan mendukung hasil pembelajaran yang menarik, inovatif dan kreatif.

Metode pembelajaran dapat diartikan sebagai cara yang dilakukan seseorang dalam mengimplementasikan metode secara spesifik. Misalnya, penggunaan metode ceramah pada kelas dengan jumlah siswa yang relatif banyak membutuhkan teknik tersendiri, yang tentunya secara teknis akan berbeda dengan penggunaan metode ceramah pada kelas yang jumlah siswanya terbatas. Demikian pula dengan metode diskusi, perlu digunakan teknik yang berbeda pada kelas yang siswanya tergolong pasif. Metode pembelajaran adalah cara konkret yang dipakai saat proses pembelajaran berlangsung. Guru dapat berganti-ganti teknik pembelajaran 
meskipun dalam koridor metode yang sama. (Komalasari, 2010:56).

Sutikno (2014:39), mengatakan bahwa macam-macam metode antara lain: metode ceramah, metode tanya jawab, metode diskusi kelompok, metode demonstrasi, metode permainan (games), metode kisah/cerita, team teaching, peer teaching, metode karya wisata, metode tutorial, metode suri tauladan, metode kerja kelompok, metode penugasan, brain storming (curah pendapat), metode latihan, metode eksperimen, metode pembelajaran dengan modul, metode praktik lapangan, micro teaching, dan metode simposium.

Ditambahkan juga proses belajar mengajar adalah proses komunikasi, penyampaian pesan dari pengantar ke penerima. Pesan berupa isi atau ajaran yang dituangkan ke dalam simbolsimbol komunikasi baik secara verbal maupun nonverbal. Proses tersebut dinamakan encoding. Penafsiran simbol-simbol komunikasi tersebut oleh peserta didik dinamakan encoding.

Belajar juga merupakan proses manusia untuk mencapai berbagai macam kompetensi, ketrampilan dan sikap. Belajar merupakan aktifitas yang dilakukan seseorang untuk mendapatkan perubahan dalam dirinya melalui pelatihan-pelatihan atau pengalamanpengalaman. (Baharuddin dan Esa NW, 2010: 11).

\section{Metode Berbasis Software}

Pada penelitian sebelumnya pernah ada kajian tentang media pembelajaran berbasis fruity loops dan juga software dalam kaitannya dengan proses pembelajaran tata suara. Menurut Yunanto dalam jurnal Studi Komunikasi Unitomo (2017: 253-261) mengatakan bahwa software merupakan salah satu perangkat penting dalam proses pembelajaran yang digunakan era modern saat ini, baik untuk peningkatan teknologi maupun sebagai media pembelajaran. Fruity Loops merupakan salah satu media pembelajaran berbasis teknologi digital berbentuk softaware yang digunakan dalam menulis dan menciptakan karya ataupun aransemen pada seni musik dalam bentuk partisi dan audio.

Yunanto dalam jurnal Terob Sekolah Tinggi Kesenian Wilwatikta (STKW) juga menambahkan aransemen merupakan bagian penting dalam seni musik. Pada hakekatnya nilai harmonisasi yang dibuat dalam mengembangkan kreativitas seni musik melalui: 1. Bentuk komposisi musik, 2. Ide garapan pada seni musik. 3. Konsep perancangan pada seni musik,
4. Pola dan metode aransemen, 5. Hasil karya cipta dalam bentuk musikal untuk menghasilkan irama dan harmonisasi dalam menciptakan musik yang indah. (Yunanto, 2017: 2).

Ditambahkan pula menurut Yunanto dalam jurnal Icitas Institut Bisnis dan Informatika Stikom Surabaya mengatakan bahwa sibelius is a software the result achieved by using the software sibelius is to produce a qualitative copyrighted work, either in the creation of the composition of the work or the arrangement of the composition of the work so that there is maximum result in the creation of the work and have a good composition value and deserve the intellectual property and copyrighted works protected by law. (Yunanto, 2018: 35).

\section{METODE}

Observasi penelitian dilakuan pada Institut Bisnis dan Informatika Stikom Surabaya. Sampel diambil dan yang digunakan adalah Institut Bisnis dan Informatika Stikom Surabaya. Analisis data yang didapatkan berdasarkan sampel pada tahun 2016. Melalui uji sampel materi yang dikembangkan sehingga dapat menentukan metode yang digunakan yaitu metode kualtitatif deskriptif.

Penelitian deskriptif kualitatif ditujukan untuk mendeskripsikan dan menggambarkan fenomena-fenomena yang ada, baik bersifat alamiah maupun rekayasa manusia yang lebih memperhatikan mengenai bentuk karakteristik, kualitas keterkaitan antara kegiatan. Selain itu penelitian deskriptif tidak memberikan perlakuan, manipulasi atau pengubahan pada variabel-variabel yang diteliti, melainkan menggambarkan suatu kondisi yang pada adanya. Satu-satunya perlakuan yang diberikan hanyalah penelitian itu sendiri, yang dilakukan melalui observasi, wawancara dan dokumentasi. (Nana Syaodih Sukmadinata, 2011:73). Metode kualitatif deskriptif untuk mengetahui keseseuaian pengembangan pembelajaran melalui beberapa capaian yang meliputi fenomena, studi kelas dan beberapa faktor lainnya.

\section{HASIL DAN PEMBAHASAN}

Berdasarkan data-data yang diperoleh dari sampel dan wawancara, maka perlunya inovasi dalam menggunakan yang berbasis pada instrumen dengan menggunakan musik software untuk komposisi dan aransemen. Pada studi kasus ini terdapat beberapa kemudahan yang dilakukan selain dengan menggunakan cara analog, adalah dengan cara membuat komposisi dan juga aransemen dengan cara digital, banyak 
software yang bisa digunakan, antara lain: sibelius software, protols, cubase, nuendo dan juga lainnya.

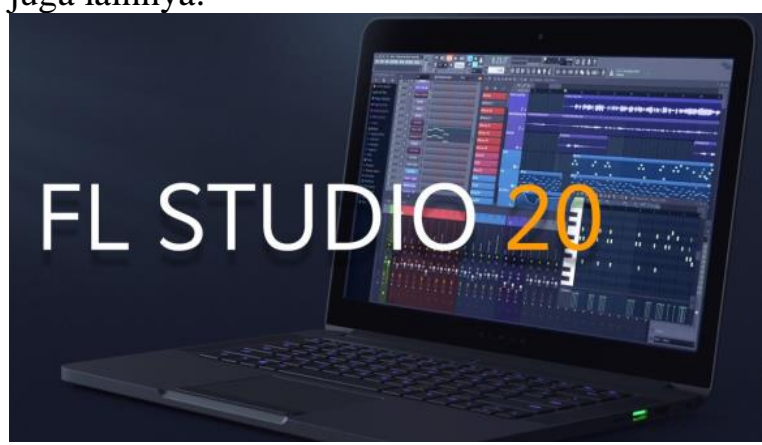

Gambar 1. Cover Fruity Loops

(Sumber: http://gistjunction.com)

Pada gambar 1 terdapat cover software fruity loops 20. Fruity loops secara fungsi pada awalnya hanya sebagai musik looping pada pada DJ, namun seiring modernisasi pada musik software fruity loops pun berbenah pada template dan fungsi lebih khsusus dalam membantu untuk mempermudah dalam menciptakan komposisi dan aransemen.

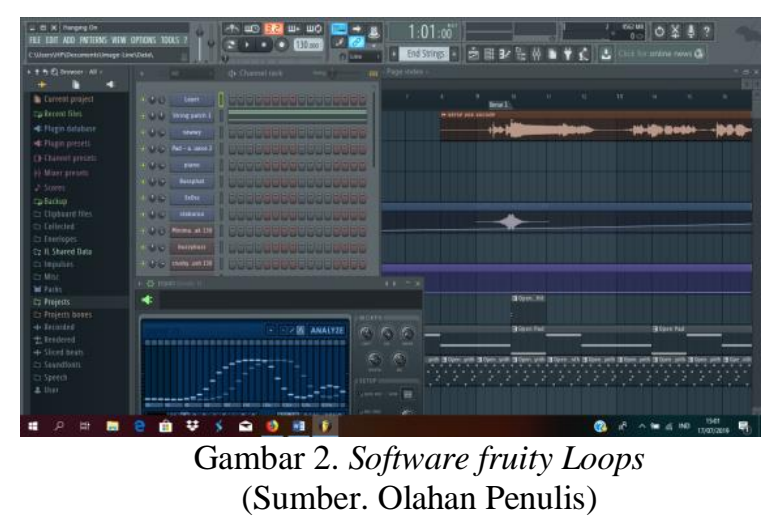

Gambar 2, merupakan hasil komposisi dan aransemen yang dihasilkan dengan menggunakan fruity loops, pada tugas mata kuliah tata suara mahasiswa Desain Komunikasi Visual (DKV) 2019. movement 1.

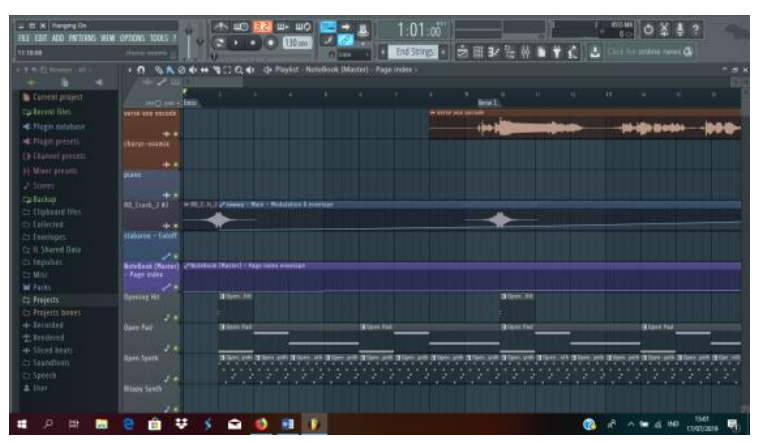

Gambar 3. Software fruity Loops

(Sumber. Olahan Penulis)

Gambar 3, merupakan bentuk komposisi musik dengan mengambil beberapa instrumen musik, yaitu layer, string patch 1, sawwy, pad ambience 2, piano, basspath, 3xOsc, stabaroo, minimal break 130, buzzy buzz, crushy mush 130, hanging on kit, funkbreak, CHR-Aah-A3, chorus voxmix, verse vox vocode, wvtrvlr, RD Crash 2, Hit 4, Hit 5, Hit 3, whistle, drop, 3xosc. movement 2.

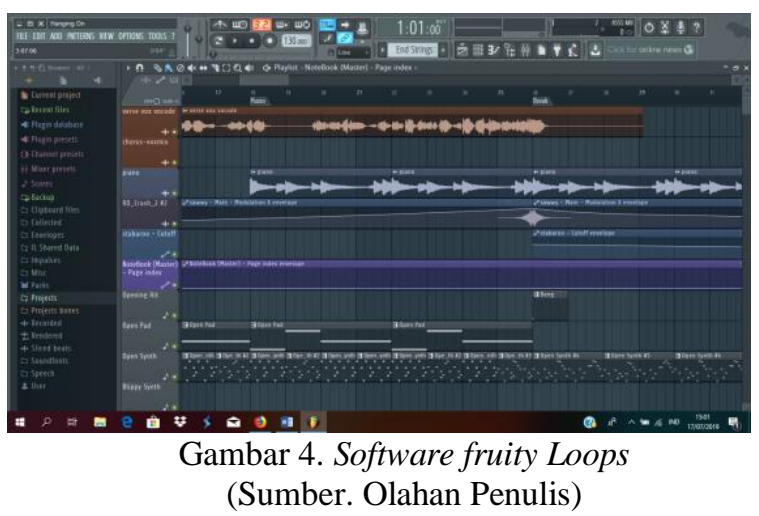

Gambar 4, movement 3 dari masing-masing bagian pada komposisi musik dengan judul "Hanging Out".

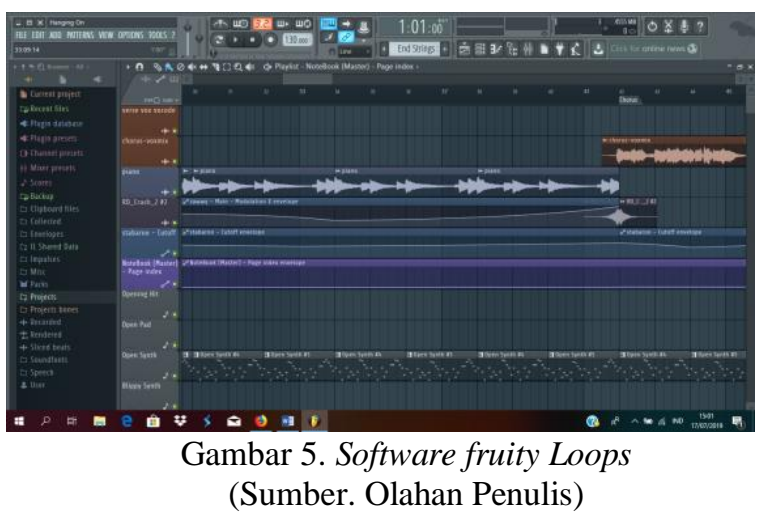

Gambar 5, movement 4 penggambaran suara dengan menyesuaikan bentuk dan pola iklan produk yang disesuaikan dengan produk iklan yang akan dipublikasikan. 


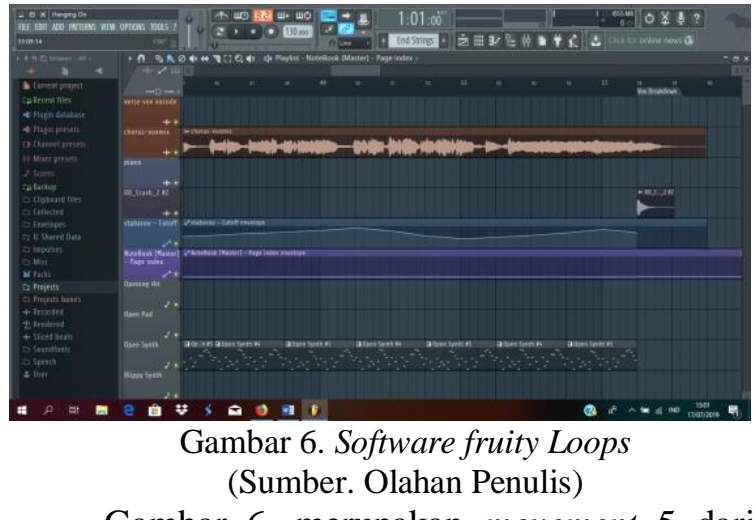

Gambar 6, merupakan movement 5 dari komposisi untuk menentukan klimaks agar ada penyesuaian dari closing pada iklan.

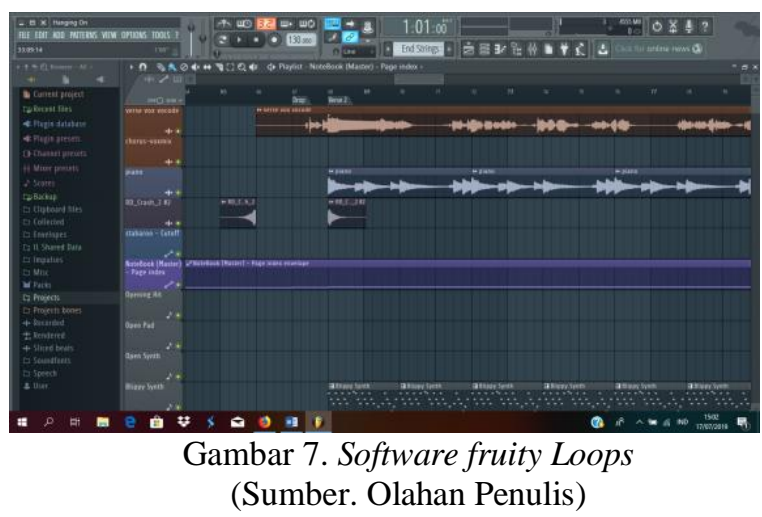

Gambar 7, merupakan movement 6, atau movement terakhir dimana target capaian dari komposisi suara dapat membantu memberikan efek visual pada iklan produk yang ditayangkan pada media sosial.

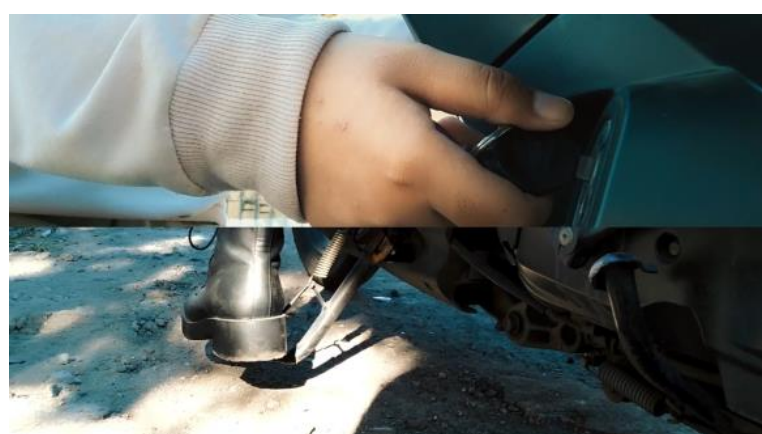

Gambar 8. On frame Camera

(Sumber. Olahan Penulis)

Gambar 8, merupakan bentuk konsep pengambilan gambar dengan memadukan penggunaan kamera agar angle yang dihasilkan sesuai dengan visual yang menarik dengan metode editing straight cut. Pada gerak dan perpindahan semula close up dirubah menjadi long shot, sehingga dapat memperlihatkan suasana pada tiap scene yang dibuat, dan lebih establish.

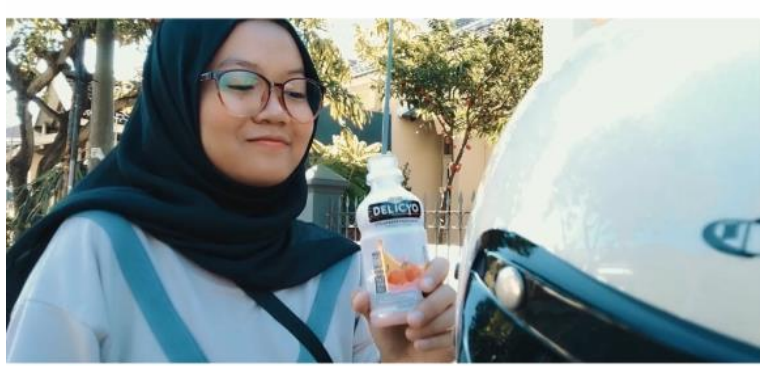

Gambar 9. On Frame Camera (Sumber. Olahan Penulis)

Gambar 9, merupakan gambar secara visual dengan menggunakan pengambilan model iklan dengan teknik long shoot. Agar memperindah tampilan pada produk iklan.

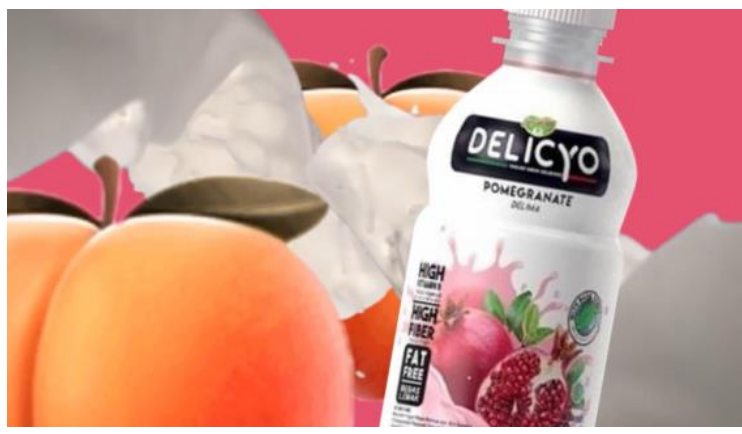

Gambar 10. On Frame Camera (Sumber. Olahan Penulis)

Gambar 10, merupakan gambar produk iklan disesuaikan dengan desain dasar sehingga menghasilkan tampilan yang disesuaikan dengan market place.

\section{SIMPULAN}

Dari hasil penelitian yang dilakukan, penjabaran yang dihasilkan secara umum adalah memberikan pemetaan tentang deskripsi tentang perancangan komposisi dan aransemen, penggunaan softaware yang efektif dan lebih mudah dipahami dengan background dasar musik, implementasi model pembelajaran berbasis software khsususnya software musik fruity looops pada mata kuliah tata suara di Institut Bisnis dan Informatika Stikom Surabaya.

Bentuk dan model pembelajaran berbasis software ini dikembangkan dan di implementasikan kepada mahasiswa yang memiliki kompetensi pengembangan khsusunya terkait bidang produksi film, TV, desain komunikasi visual, dan juga animasi. Dalam hal ini sebagai fasilitator bagi pengembangan dalam media industri kreatif yang lebih variatif, namun tidak meninggalkan bentuk instrumen yang konvensional mengacu pada pengembangan industri kreatif. 
Deskripsi pemetaan tersimpulkan dalam 3 bagian yaitu:

(1) Memberikan pola pada pengalaman pembelajaran dalam bentuk digital software melalui bentuk variasi, inovasi dan pengembangan komposisi dan juga aransemen. Namun secara pelestarian kebudayaan masih bisa dilestarikan dengan baik melalui pengembangan tata suara pada film, TV, animasi dan juga desain komunikasi visual.

(2) Media serta model pembelajaran disesuaikan dengan kemampuan mahasiswa dalam menerima respon dalam proses pembelajaran, sehingga dapat menumbuhkan pola dan kreativitas mahasiswa.

Bentuk penelitian dilakukan secara deskriptif yaitu melalui studi kasus di kelas, wawancara, melakukan pengamatan dan juga melakukan eksperimen.

Diharapkan dengan hasil ini mahasiswa dapat lebih bertanggung jawab dalam produksi tata suara serta memiliki kepekaan tentang musik daerah dan juga diharapkan lebih produktif dalam menciptakan komposisi dan aransemen.

\section{DAFTAR PUSTAKA}

Baharuddin dan Esa Nur Wahyuni. 2010. Teori Belajar dan Pembelajaran. Yogyakarta: Ar-Ruzz Media.

B. Hamzah dan Nurdin. 2011. Belajar Dengan Pendekatan Pailkem. Jakarta: PT. Bumi Aksara.

Gaspersz, Vincent. 2004. Production Planning and Inventory Control, Cetakan Keempat. Jakarta: Gramedia.

Komalasari, Kokom. 2010. Pembelajaran Kontekstual: Konsep dan Aplikasi. Bandung: Refika Aditama.

Komalasari, Kokom. 2013. Pembelajaran Kontekstul: Konsep dan Aplikasi. Bandung: PT Refika Adiatama.

Sarwono, S.W. 2002. Psikologi Remaja. Edisi Revisi 8. Jakarta: Raja Gravindo Pustaka.

Sukmadinata, Nana Syaodih. 2011. Metode Penelitian Pendidikan. Bandung: PT Remaja Rosdakarya.

Sutikno, Sobry. 2014. Metode dan Model-Model Pembelajaran Menjadikan Proses Pembelajaran Lebih Variatif, Aktif, Inovatif, Efektif, dan Menyenangkan. Lombok: Holistica.

Yunanto Tri Laksono. (2017). Penerapan Aplikasi Fruity Loops Sebagai Media Pembelajaran Penciptaan Komposisi dan
Aransemen Tata Suara. Volume 1 No. 3, 253-261. Jurnal Studi Komunikasi.

Yunanto Tri Laksono. (2017). Sibelius Software Sebagai Media Aransemen Pada Kelompok Musik Keroncong Kurmunadi di Surabaya. Volume 7, No 2. Jurnal Terob. 